\title{
Health Budgeting at Woreda level and Effect on Access and Quality of Health Services in Somali Region of Ethiopia
}

\author{
Oladeji Olusola $^{1 *}$, Pieterse Pieternella ${ }^{2}$, Robins Ann ${ }^{3}$, Oladeji Bibilola ${ }^{4}$ \\ ${ }^{1}$ UNICEF Somali Field Office, Ethiopia \\ ${ }^{2}$ Dublin City University, Ireland \\ ${ }^{3}$ UNICEF Country Office, Ethiopia \\ ${ }^{4}$ College of Medicine, University of Ibadan, Nigeria
}

\begin{abstract}
Ethiopia has made a great effort in recent years to improve maternal, newborn, child health outcomes, however, the uptake of services in Somali Region of the country is still very low. The study was a cross-sectional descriptive survey using qualitative methods, and the participants were key individuals involved in the management of health systems and knowledgeable about on health service delivery in the study sites. The study aimed to explore the budgeting process at the woreda (district) level and its effect on the utilization of equitable quality health services in the region. The woreda health officers determined what is included in the budget of the health facilities without active participation of stakeholders such as health care providers or the community members. Their knowledge and understanding of the planning and budgeting processes varied and little or no support available to them. This suboptimal budgeting process impacts negatively on the quality of health care services being provided, with shortages of essential drugs identified as a major barrier affecting utilization. The need for better budgeting process at the woreda level which could perhaps involve a range of regional level, woreda level and citizen level measures and active participation. This include the implementation of clearer guidelines from regional level, maybe the introduction of standard formulae that ensures that each health centre receives certain percent of overall health budget and specific percentage to be allocated for drugs and supplies and other essential services instead of each woreda official deciding on how much is to allocated arbitrarily.
\end{abstract}

Keywords: accountability, budget, health, participation, woreda.

\section{Introduction}

Ethiopia has made great efforts in recent years to improve maternal, newborn, and child health $(\mathrm{MNCH})$ outcomes with the implementation of the country's health-sector transformation plan and other strategic initiatives that have driven a steady decline in maternal, newborn, infant, child and under five mortality [1].

Improvements in health outcomes have been positively influenced by the government's policy support for the Health Extension Program (HEP) especially the engagement of Health Extension Workers (HEWs), which has contributed to health promotion, disease prevention and community-based disease case management, leading to the reduction of morbidity and mortality [2]. Ethiopia was one of the low-income countries to have achieved the Millennium Development Goal four (MDG 4) target of reducing child mortality by twothirds (from 204 per 100,000 in 1990, to 68 per 100,000 in 2012) [1]. The maternal mortality has also significantly reduced to about 412 per 100,000 live births in 2016 from 676 per 100,000 livebirths in 2011 [3] and this has been attributed to the successful implementation of the country flagship health extension program [4].

However, Somali Region, which is one of Ethiopia's four Developing Regional States (DRS) and predominantly inhabited by pastoralists (85\%), faces developmental inequities and has shown less improvement in key health outcomes compared to the national average [5].

The 2019 Mini DHS records that Somali Region has the lowest percentage of fully vaccinated children, with only $18.2 \%$ having 
received all basic vaccinations, and $48.8 \%$ had received no vaccinations at all compared to the national average of $43.1 \%$ and $19.2 \%$ respectively [6]. Ethiopia has a decentralized health system and has introduced a series of institutional and policy reforms in the public sector aimed at capacity building, enhancing government responsiveness to citizens and implementation of the principles of good governance in the health sector include rule of law, transparency, inclusiveness and equity, responsiveness, efficiency and effectiveness and participatory engagement of citizens [5].

This study aims to explore the budgeting process at the woreda level in Somali Region and its effect on the quality and utilization of equitable health services in the region and identify innovative approaches for improving budgeting processes in the region.

\section{Materials and Methods}

The study was a cross-sectional descriptive survey using qualitative methods.

The study was conducted in 3 woredas (Gursum, Awbare and Kebribayah) and 2 municipal areas (Jijiga and Wachale) in Farfan zone in the region where social accountability mechanism in the health sector was being introduced by government. The study area has a total estimate population of 746,046 and 86 health facilities.

The study population included the key persons at the community, health facility, woreda/municipal offices, and the regional office with an active role in health care delivery, planning and budgeting in the study sites. The different respondent groups were identified, guided by the World Bank's framework on accountability: policy advisors, healthcare officials, healthcare providers, and citizens [7].

The study focused on assessing the budgeting process in a decentralised health system by reviewing the linkages and relationship between the region, woreda and the community and the perception of the community members on the effect of budgeting on health service delivery, especially on availability of essential drugs, supplies and vaccines.

The participants were purposefully identified and recruited based on their positions and roles in the management of health systems and knowledge of health service delivery in the study sites.

Data was collected through in-depth interviews and focus group discussions (FGDs). The in-depth interviews aimed at identifying the budgeting process at the woreda level. Decision makers involved in the budgeting process were asked about budget planning and budget execution, and how it affects health service delivery in the study sites. The FGDs aimed at identifying the perception of the beneficiaries on the utilization and quality of care provided in the health facilities. The FGDs with women groups were audio-taped and notes were also taken with prior consent from the participants. The study was conducted between December 2019 and January 2020.

The FGD data was collected from different categories of respondents and responses to the same questions were triangulated and transcribed verbatim to produce transcripts of narrative text for thematic analysis. The data were coded according to the types of themes and issues, and thematic analysis was used and comprised a mix of inductive and deductive coding. The outcome of the study was the woreda-based budgeting process and management and effect on quality of health service delivery were transcribed and initially presented as a series of case studies.

\section{Results}

The results are organized in two major themes: Budget planning process and implementation and the perception of beneficiaries about the quality of health services delivery.

Overview of the respondents: Table 1 shows the categories of the respondent interviewed durimg the study. These were the head of the planning, budgeting and $M \& E$ at the region, the heads of the woredas/municipal health offices, head of finance in one of the woredas, the heads of health centres and health posts in the five study sites and the representative of the women groups and selected women /care givers in three of the study sites. 


\section{The Health Budget Planning Process in Somali Region}

\section{The Funding Chain for the Health Sector in Ethiopia}

Figure 1 shows the funding chain for primary healthcare funding from the treasury in Ethiopia flows from national to regional, then to woreda/municipal and finally to health centers, which support the health posts as explained by the planning and budgeting officer at the regional level. There are only two types of primary healthcare facilities in Somali Region, health centers and health posts with each health centre responsible for a range of between $4-8$ health posts.

\section{Budget Planning Process and Implementation}

The budget cycle as described by the regional planning and budgeting officer is initiated at the regional level as follows; the Regional Bureau of Finance and Economic Development (BOFED) provides each woreda BOFED with indicative budget estimate; the Woreda BOFED asks for the budget estimates from all woreda sector offices, and the Woreda BOFED will then create budget suggestions after all of the sector heads have defended their budget. The proposed budget then goes to the woreda cabinet, which is entirely made up of the same sector heads who proposed the budget, which leads to an almost certain guarantee that the budget will be approved. Once the budget allocation to each sector within each woreda has been agreed, it is then sent to the regional bureaus and parliament for approval.

Once the woreda health office receives the indicative annual budget, it is at their discretion to allocate a running cost to each health centre, or not, and to divide the non-recurrent budget. The regional health bureau team focuses more on the technical performance of the woreda health facilities, measured through monthly statistics reported by the health facilities, rather than paying close attention to the financial performance of each woreda's administration of each of the 99 woredas in Somali region. However, extreme budgeting issues are questioned; a member of the regional health bureau explained:

'Sometimes the woreda budgets are so badly structured that the regional health bureau intervenes, overall, this is rare. For example, at some time in the past a woreda health officer had planned to spend the entire annual capital budget for his woreda on new office furniture, which was blocked by the regional health bureau. Unfortunately, there are few checks on how budgets are divided there are few checks regarding the financial performance of woredas'.

\section{Woreda/Municipal office}

The five woreda/municipal officials interviewed explained how the budget cycle works in their respective woreda/municipal areas. The finance office (at the woreda level) has the mandate to allocate budget according to the needs of the people. The cabinet delegates these decisions to the finance office, and the head of the finance office are a member of the cabinet. The finance office forwards the suggestions about the division of the budget at woreda level to the cabinet for approval. There is no participation of most of the key stakeholders like the community members, the board members overseeing the health centers, and the officers in charge of the health post during the budget discussion and planning process.

Each woreda health office leadership team decides on a budget for the essential drugs and supplies and there is no uniformity or any clear criteria that guides how much is allocated to each key subsection of health such as maternal and child health, disease prevention, immunization, etc. Within the five study sites, one woreda health office budgeted 500,000 ETB per annum for the revolving fund to purchase medications for the single health centre in that woreda, while another woreda health office budgeted 800,000 ETB per annum for the health centers in the woreda to share.

One of the officers explained further on how the budgeting process is done:

'The regional finance bureau allocates the amount to the municipality that they deem necessary, often based on previous years' budgets, and the total figure goes back to the municipal council. They decide on how the total sum that they have been allocated gets subdivided among all the sectors. The subdivision does not work according to any formula, it is more a case of "you got some money for construction last year, so we will 
provide more to the other sectors this year. It is then up to the sector heads to decide to further divide the funds that have been allocated' [Municipal Key Informant 1].

Most of the woreda officials mentioned that frequently not all of the approved budget is released to the woreda and the health centres in time and that there is always a delay in the release of approved budget from the region to the woredas.

\section{Health Centres}

During interviews with the head of the health centres, two concerns were highlighted; insufficient funds were being allocation for drugs and supplies, and low or no running cost are allocated or received for the health centres, which is to be shared with the health posts under each health centre. The experiences about budget releases varied from one health centre to the other. The five locations sampled included a health centre in one of the municipal areas which received running cost as per the budget, while other health centres received much less than the budgeted amount, and all reported delays in receiving funds. The running cost per health centres varied from 10,000- 20,000 ETB per month without no clear criteria on how this is determined.

However, shortages of drugs and other essential supplies were a major problem common to all the health centres. Health centre senior staff admitted:

'The medicines are always a problem, the amount of money spent on budget drugs is small, still based on the old population figures, and with patients from Somaliland crossing over the border to access our health centre, the medicines run out quickly' [Health Centre Key Informant 1].

'Our health centre also needs to provide free drugs to the health posts it supervises and supports, but this can be difficult when stocks are already low, so sometimes we can only provide about $40 \%$ of what a health posts ask for' [Health Centre Key Informant 2].

'Our biggest problem in the Health Centre is struggling with is the small running cost transfer to us which we are also expected to use for the health posts under us by which is even not enough for us. We always receive less than what we requested and budget and always coming late' [Health Centre Key Informant 3].
'My health centre sometimes solicits feedback from its patients, and in general the responses are positive. The usual and most common complaints from the patients is shortage of drugs, which is due to the insufficient amount allocated to drugs in our budget by the woreda without telling us why' [Health Centre Key Informant 4].

\section{The Health Posts}

Ethiopia's Health Extension Program (HEP), which has been lauded for bringing basic primary healthcare delivery closer to the communities, depends on the services of Health Extension Workers (HEWs), who are based at Health Posts in kebeles (communities) throughout Ethiopia. As noted, health posts are dependent on their nearest health centre for their drug supplies and running costs. As these were found to be in short supply in the health centres, it was not surprising that the issues were even more severe in the health posts that were visited. HEWs locations complained about not having a running cost budget and being dependent on the irregular supply of the health centre for even basics such as cleaning products and stationery, as well as medicine.

The lack of running costs at the health post level appears to affect the provision of services especially for transportation to pick up medicines or vaccines from the woreda health office or to go on outreach to immunise children in the communities close to the health post.

\section{Perception of Beneficiaries about Quality of Health Service Delivery}

The views of the women in the community on the quality of health services being provided was assessed through one of the women's group leaders and selected group of mothers/care givers. The leader of the one of the women's groups reported a good working relationship with the staffs in the health facilities, the women are happy with the services provided to them, but most of the complaints by the women when they visit the health facilities is about drugs supply.

'We have a good relationship with the health workers and anytime we go to them to raise complaint like when we bring a labouring mother to a health centre and she does not receive immediate attention or lack of drugs or 
vaccines in the clinic. We understand the problem of drugs or vaccines is from the woreda or health centre who bring little drug or vaccines to the clinics [Women's Group Key Informant].

The women in the focus group discussion revealed that, after facing the challenges of getting to the health facilities by all means because many of them live far away from the health facilities, they are disappointed to see the clinics not opened or not provided with all the needed services and drugs or vaccines. One of the women group members expressed her concern:

'In the clinic in our kebele the number of drugs is small and gets used up quickly and so we usually don't get treatment when we or children feel sick and because of that some women don't come to the clinic again' [Women group member during FGD].

\section{Discussion}

Universal health coverage requires an efficient health system that provides the entire population with access to good quality services, provided by sufficient health workers, who have accessed the requisite medicines and technologies.

This study shows that during our examination of the funding chain that runs from the national level, via region, woreda/municipality, to health centre and health posts, it appears that there are serious constraints with regards to the budget process at woreda and municipal level. At this level, a relatively small group of individuals determine what should be included in the budget without participation of other stakeholders like the community members and health care providers. This appears to be a suboptimal way of budget making, which undermines the quality of health service delivery in Somali Region and disadvantages the most vulnerable in society who need access to basic primary healthcare most.

In addition to the budget process lacking active engagement from the healthcare professionals who are charged with delivering health services in Somali Region, the process also lacks input from those community members who use the health services. This is against the principles of primary health care which recommended community participation in all the processing leading to the planning and budgeting of health care delivery for the communities. Community participation has been recognized as an important public health policy since the declaration of Alma-Ata presented it as one of the pillars of primary health care in 1978 [8] and reaffirmed 40 years after during the primary health care conference in Astana [9]. The Ottawa Charter for Health Promotion [10] and Jakarta Declaration [11], and most importantly the Ethiopian Government's own 5th Health Sector Transformation Plan, Strategic Objective P3 is 'Enhance Good Governance' [5] which all emphasize the importance of community participation as a key principle for effective health system strengthening.

Our study found that the woreda health officers' knowledge and understanding of the planning and budgeting process varied, and their understanding of the health sector needs seemed to be related to how much funding was allocated for key interventions like drugs supplies and running cost, compared to spending on the woreda health office's own needs. There is an obvious lack of guidance regarding the management of woreda health budgets, providing woreda health office heads with significant discretion to allocate funding, which has a direct, and sometimes negative, impact on the functioning of the health facilities within its jurisdiction.

This is like findings in other countries in the region which have reported limited knowledge and skills in planning among local government authority staff and councillors as among the challenges facing the implementation of decentralization in the health sector [12]. There is a need to build the capacity of woreda officers and provide institutional support to them for effective planning and budget management.

Introducing greater citizen engagement in the health sector needs to be done in a gradual and structured way that takes account of Somali Region's contextual challenges when it comes to inviting women to participate in public fora. In places where active women's groups can be found, these can be entry points for further engagement. Evidence suggests that when community members are invited to fully participate in the planning and budgeting processes, a number of benefits emerge; 
including better identification of community needs and priorities, increased knowledge of the community representatives about priority setting, increased transparency and accountability, promoted trust among health systems and communities, and perceived improved quality and accessibility of health $[13,14]$. Such interventions need to be introduced with significant support to expose the community to planning skills, knowledge, and confidence to enable them to engage meaningfully during planning and budgeting process in their respective woredas so as to achieve the purpose of their participation. Selecting suitable tools for citizen participation, such as gender-responsive budgeting [15] or citizen-led audits [16] can play a positive role.

Another major concern raised in this study was the late transfer of funds from the regional level to the woreda and to health facilities, which was reported to have had a negative impact on health service delivery. Most of the woredas are unable to generate their own funds to supplement what is provided to them from them from the region. The woredas in Somali region are not the only part of Ethiopia, or indeed the continent where such challenges exist. Studies from Tanzania, Uganda, Zambia and Ghana have similarly reported such issues $[12,17,18]$, whereby the allocations to the local, often rural, health authorities and facilities are not only inadequate to support local health needs, the central government disburses grants late, causing difficulties in the implementation of health activities. With many woredas in the region enjoying the financial and technical support being provided by NGOs and $\mathrm{UN}$ agencies, there is a need for the mapping and harmonization of such resources at the regional level to ensure that these are targeted to the woredas with the greatest need and least support, for efficient, effective and equitable service delivery.

In assessing the quality of health care services being provided, the study identified budget shortages leading to a lack funding to procure enough essential drugs and supplies and to cover transportation of vaccines from the woreda or health centres to the health post or to conduct outreach visits for immunisation. All of these shortcomings present major barriers affecting the utilization and access to health services in Somali Region. The study shows that continuous availability of essential medicines in the health facilities plays an important role in promoting access to and utilization of health services as articulated by the women interviewed and this finding is similar to other studies $[9,20,21]$, which reported that frequent stock-outs of medicines influence healthcare utilization and individual decisions to consult health service providers, leading to a distrust in healthcare providers and contributes to low utilization of the formal health care system. However, the study did not assess in detail other possible causes of the shortage of drugs supply apart from what was articulated by the health workers and the beneficiaries interviewed.

The availability of quality medicines in the provision of healthcare service is an integral part of universal health coverage for efficient, quality and equitable healthcare service delivery $[22,23]$.

\section{Conclusion}

It is clear that the processes of decision making and budgeting for health at the woreda level have a direct impact on the functioning of the health facilities and utilization of services. Understanding the budgeting system from the perspective of those who are directly involved with the process is extremely important in understanding and improving health care delivery.

Such a process would greatly benefit from being more participatory and inclusive of all stakeholders, especially female community members, to ensure greater accountability.

There is a need for better budgeting process at the woreda level which could perhaps involve a range of regional level, woreda level and citizen level measures and active participation. This include, for example, the implementation of clearer guidelines from regional level, maybe the introduction of standard formulae that ensures that each health centre receives a certain percent of overall health budget and specific percentage to be allocated for drugs and supplies and other essential services instead of each woreda official deciding on how much is to allocate arbitrarily. 


\section{Figures and Tables}

Table 1: Overview of the Respondents

\begin{tabular}{|l|l|}
\hline Respondents Categories & Number \\
\hline Health adminstrators/officials & \multicolumn{2}{|l|}{} \\
\hline Planning and budgeting officer at the regional level & 1 \\
\hline Head of woreda/municipal health offices & 5 \\
\hline Head of finance at the woreda level & 1 \\
\hline Head of health centres & 5 \\
\hline Officers in charges of health post & 3 \\
\hline Community members & 1 \\
\hline Representative of the womens' group & 32 \\
\hline Care givers/mothers during FGDs \\
\hline
\end{tabular}

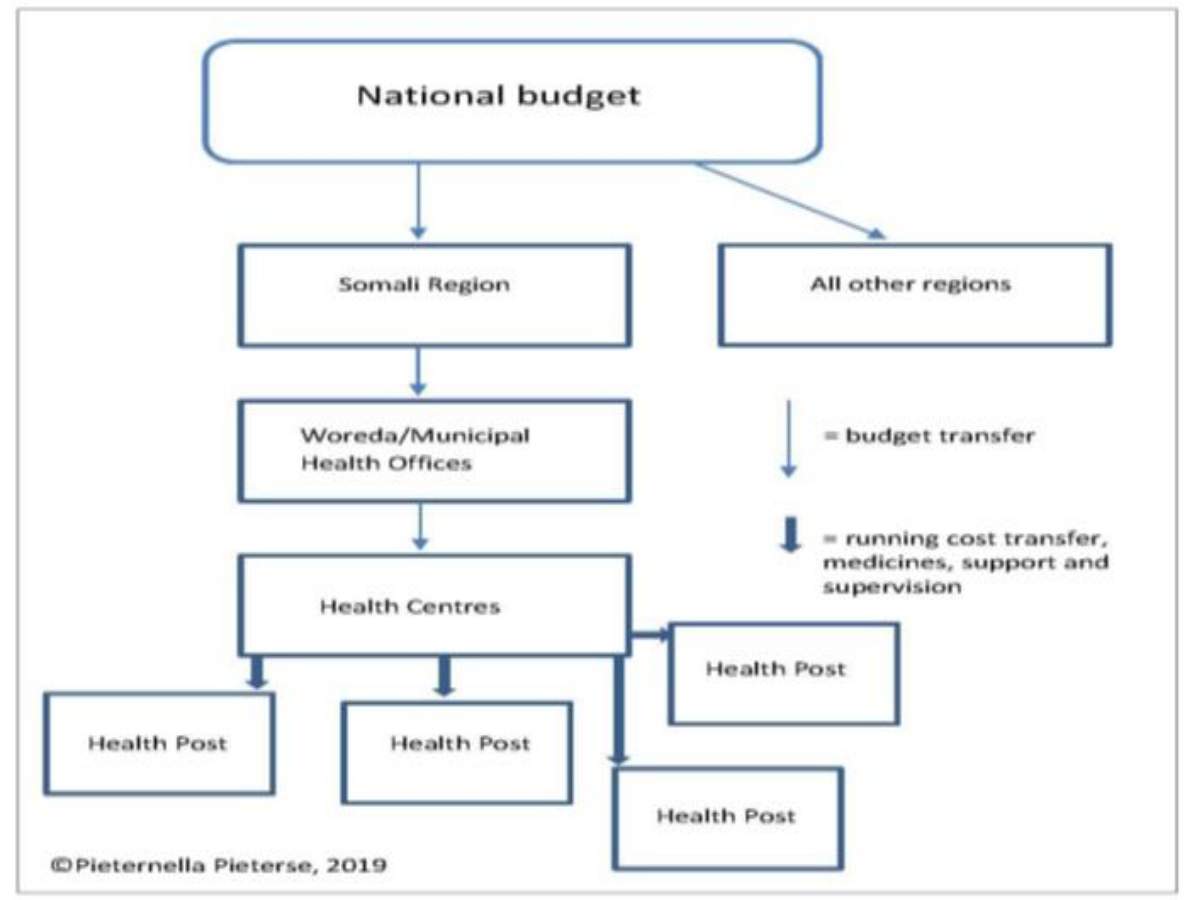

Figure 1: The funding Chain for the Health Sector in Ethiopia

\section{Acknowledgements}

The authors wish to thank all the individuals interviewed during the field work at the Regional and woreda level, including the women during the focused group discussion. We also Mohamed Ayanle Hassan, the Directorate Director of Planning, $\mathrm{M} \& \mathrm{E}$ and
NGOs Somali Regional Health Bureau who provided very useful information about the budgeting and planning process in the region and Asli Hassan, UNICEF C4D consultants who helped with interpretation during the field work. 


\section{References}

[1] United Nations. 2015, The Millennium Development Goals Report 2014, Ethiopia. Assessment of Ethiopia's progress towards the MDGs: National Planning Commission and the United Nations in Ethiopia. http://et.one.un.org/content/unct/ethiopia/en/home/as sistance-framework/millennium development goals. $\mathrm{html} /$.

[2] Assefa, Y., Gelaw, Y.A., Hill, P.S., Taye, B.W., and Van Damme, W., 2019, Community health extension program of Ethiopia, 2003-2018: successes and challenges toward universal coverage for primary healthcare services. Globalization and health; 15(1): 24. accessed 14th July 2020.

[3] Central Statistical Agency (CSA) [Ethiopia], ICF., 2016, Ethiopia Demographic and Health Survey 2016: Key Indicators Report. Addis Ababa, Ethiopia, and Rockville, Maryland, USA. CSA and ICF.

[4] Federal Ministry of Health of Ethiopia., 2010, Health Sector Development Plan (HSDP) IV, 2010/11-2014/15. Addis Ababa, Ethiopia: Ministry of Health.

http://www.nationalplanningcycles.org/sites/default/ files/country_docs/Ethiopia/ethiopia_hsdp_iv_final draft_2010_-2015.pdf.

[5] Federal Ministry of Health of Ethiopia., 2015, Ethiopia's Health Sector Transformation Plan (HSTP) (2016 -2020). https://www.globalfinancingfacility.org/ethiopiahealth sector transformation plan 201516-201920/ accessed 14th July 2020.

[6] Ethiopia Central Statistical Agency., ICF., 2019, mini-Ethiopia Demographic and Health Survey 2019. Addis Ababa, Ethiopia, and Rockville, Maryland, USA. accessed 2nd August 2020.

[7] World Bank.,2004, Making Services Work for Poor People. World Development Report 2004. Washington, DC: World Bank. https://openknowledge.worldbank.org/handle/10986/ 5986. accessed 23th September 2020.

[8] WHO., UNICEF., 1978, International conference on primary healthcare Alma-Ata, USSR, 6_12 September.https://www.who.int/publications/almaat a_declaration_en.pdf. accessed 23th September 2020.

[9] World Health Organization, United Nations Children's Fund. Declaration of Astana. Global Conference on primary health care. Astana Kazakhstan 25-26th October; 2018. https://www.who.int/docs/default-source/primary- health/declaration/gcphc-declaration.pdf accessed 23rd September 2020.

[10] World Health Organization.,1986, Ottawa charter for health promotion. Geneva: https://www.who.int/teams/healthpromotion/enhanced-wellbeing/first-globalconference. accessed 14th July 2020.

[11] World Health Organization.,1997, The Jakarta declaration: on leading health promotion into the 21st century. Geneva. https://www.who.int/healthpromotion/conferences/p revious/jakarta/declaration/en/ accessed 14th July 2020.

[12] Gasto, F., Tumaini, N., Mughwira, M., and Anna-Karin, H., 2013, Challenges to the implementation of health sector decentralization in Tanzania: experiences from Kongwa district council, Global Health Action; 6:1, DOI: 10.3402/gha. v6i0.20983. accessed 14th July 2020.

[13] Kamuzora, P., Maluka, S., Ndawi, B., Byskov, J., and Anna-Karin, H., 2013, Promoting community participation in priority setting in district health systems: experiences from Mbarali district, Tanzania, Global Health Action; 6:22669- DOI: 10.3402/gha. v6i0.22669 accessed 14th July 2020.

[14] McCoy, D., Hall, J., Ridge, M., 2012, A systematic review of the literature for evidence on health facility committees in low-and middleincome countries. Health Pol Plann; 27: 449-466.

[15]Nass, L., and Pieterse, P., 2018 Gender Responsive Budgeting in Ethiopia's Country-wide Social Accountability Program. Research Gate. https://www.researchgate.net/publication/327261578 accessed 14th July 2020.

[16] Mugizi, G. Interrogating Social Accountability in Tanzania, a Case Study. The PSAM and Policy Forum Learning Partnership August 2009 - April 2013. Public Service Accountability Monitor, Grahamstown, South Africa: Rhodes University;2013.

[17] Jeppsson, A., Okuonzi, SA.,2000, Vertical or holistic decentralization of the health sector? Experiences from Zambia and Uganda. Int J Health Plann Manage; 15(4): 273-89. https://pubmed.ncbi.nlm.nih.gov/11246898/ accessed 14th July 2020.

[18] Kojo, E., Sakya, J., Awoonor-Williams, K., Adzei, FA., 2011, Barriers to implementing health sector administrative decentralization in Ghana: a study of the Nkwanta district health management team. J Health Organ Manag; 25: 400.

[19] Shan, L., Li, Y., Ding, D., Wu, Q., Liu, C., Jiao M, et al.,2016, Patient Satisfaction with Hospital 
Inpatient Care: Effects of Trust, Medical Insurance and Perceived Quality of Care. PLoS ONE 11(10): e0164366.

https://doi.org/10.1371/journal.pone0164366.

[20] Anselmi, L., Lagarde, M., and Hanson, K. Health service availability and health seeking behaviour in resource poor settings: evidence from Mozambique. Health Economics Review; 5:26. https://www.ncbi.nlm.nih.gov/pmc/articles/PMC455 $6719 /$.

[21] Musoke, D., Boynton, P., Butler, C., and Musoke, MB., 2014, Health seeking behaviour and challenges in utilising health facilities in Wakiso district, Uganda. Afr Health Sci ;14(4): 1046-55.doi: 10.4314/ahs. v14i4.36.
[22] Bigdeli, M., Laing, R., Tomson, G., and Babar, ZU., 2015, Medicines and universal health coverage: challenges and opportunities. Journal of Pharmaceutical Policy and Practices; 8: 8. https://joppp.biomedcentral.com/articles/10.1186/s4 [23] 0545-015-0028-4.accessed 26th August 2020. [24] Obare, V., Brolan, CE, Hill, PS., 2014, Indicators for universal health coverage: can Kenya comply with the proposed post-2015 monitoring recommendations? Int J Equity Health 13, 123. https://doi.org/10.1186/s12939-014-0123-1. accessed 26th August 2020\. 